\title{
Cardiac mast cell-derived renin promotes local angiotensin formation, norepinephrine release, and arrhythmias in ischemia/reperfusion
}

\author{
Christina J. Mackins, ${ }^{1}$ Seiichiro Kano,1 Nahid Seyedi,, Ulrich Schäfer, ${ }^{1}$ Alicia C. Reid,² \\ Takuji Machida, ${ }^{1}$ Randi B. Silver, ${ }^{2}$ and Roberto Levi ${ }^{1}$
}

1Department of Pharmacology and 2Department of Physiology and Biophysics, Weill Medical College of Cornell University, New York, New York, USA.

\begin{abstract}
Having identified renin in cardiac mast cells, we assessed whether its release leads to cardiac dysfunction. In Langendorff-perfused guinea pig hearts, mast cell degranulation with compound 48/80 released Ang I-forming activity. This activity was blocked by the selective renin inhibitor BILA2157, indicating that renin was responsible for Ang I formation. Local generation of cardiac Ang II from mast cell-derived renin also elicited norepinephrine release from isolated sympathetic nerve terminals. This action was mediated by Ang II-type 1 $\left(\mathrm{AT}_{1}\right)$ receptors. In 2 models of ischemia/reperfusion using Langendorff-perfused guinea pig and mouse hearts, a significant coronary spillover of renin and norepinephrine was observed. In both models, this was accompanied by ventricular fibrillation. Mast cell stabilization with cromolyn or lodoxamide markedly reduced active renin overflow and attenuated both norepinephrine release and arrhythmias. Similar cardioprotection was observed in guinea pig hearts treated with BILA2157 or the $\mathrm{AT}_{1}$ receptor antagonist EXP3174. Renin overflow and arrhythmias in ischemia/reperfusion were much less prominent in hearts of mast cell-deficient mice than in control hearts. Thus, mast cell-derived renin is pivotal for activating a cardiac renin-angiotensin system leading to excessive norepinephrine release in ischemia/reperfusion. Mast cell-derived renin may be a useful therapeutic target for hyperadrenergic dysfunctions, such as arrhythmias, sudden cardiac death, myocardial ischemia, and congestive heart failure.
\end{abstract}

\section{Introduction}

In addition to the classic circulating renin-angiotensin system (RAS) (1,2), many tissues, including the heart, possess a local RAS that may mediate autocrine, paracrine, and intracrine effects (2-4). All RAS components have been identified in cardiac tissue $(5,6)$. Consequently, local Ang II concentrations may exceed those of plasma levels and play important roles in the control of cardiac function (7) and in cardiac pathophysiology, such as hypertrophy and infarction $(8,9)$. In fact, local Ang II production is known to increase in the ischemic myocardium (10).

Before our discovery that mast cells express renin protein in the intact heart (11), evidence for the localization of cardiac renin was suggestive and limited to nonintact systems. Indeed, renin mRNA and protein had been detected in cultured canine cardiac myocytes (12), and renin mRNA had been reported in fibroblasts as well as endothelial and coronary vascular smooth muscle cells $(5,6,13)$. In patients with acute and previous myocardial infarctions, the left ventricle was found to have significantly elevated levels of renin mRNA (13). In rats, renin mRNA expression increased in the border zone of infarcted left ventricle (14). However, demonstration that this renin mRNA leads

Nonstandard abbreviations used: $\mathrm{ACE}$, angiotensin-converting enzyme; $\mathrm{AT}_{1}$, angiotensin II receptor, type 1; KH, Krebs-Henseleit; NE, norepinephrine; RAS, renin-angiotensin system; VF, ventricular fibrillation; VT, ventricular tachycardia.

Conflict of interest: A patent for related technology has been filed with the US Patent and Trademark office by Cornell University. R. Levi and R.B. Silver are coinventors. Citation for this article: J. Clin. Invest. 116:1063-1070 (2006). doi:10.1172/JCI25713. to synthesis of active renin protein capable of driving local production of Ang II has been lacking.

We recently reported that mast cells in fixed and frozen sections of intact rat heart were immunopositive for renin (11). Further supporting this observation, the human mast cell line HMC-1 also expressed and synthesized renin protein (11). When released upon degranulation, this renin was capable of generating Ang I from angiotensinogen (11). These findings suggest that mast cells are a source of extrarenal renin, which, when liberated, could initiate the local formation of Ang II. By activating angiotensin II receptor, type $1\left(\mathrm{AT}_{1}\right)$ receptors on sympathetic nerve terminals, Ang II enhances norepinephrine (NE) exocytosis (15) and elicits carrier-mediated $\mathrm{NE}$ release by stimulating the neuronal $\mathrm{Na}^{+} / \mathrm{H}^{+}$ exchanger (16). Inasmuch as mast cells are known to degranulate in myocardial ischemia $(17,18)$, we have now investigated and determined that release of mast cell renin activates a local cardiac RAS, thereby promoting NE release and arrhythmic cardiac dysfunction in ischemia/reperfusion.

\section{Results}

Release of renin from guinea pig heart mast cells: local RAS activation and $N E$ release from sympathetic nerves. Ex vivo, Langendorff-perfused guinea pig hearts were challenged with the mast cell-degranulating agent compound 48/80 $(19,20)$, and overflow of Ang I-forming activity was measured in the coronary effluent. As shown in Figure 1B, compound 48/80 (300 $\mu$ g bolus) augmented the overflow of Ang I-forming activity approximately 5-fold over baseline. When hearts were perfused with the selective renin inhibitor 

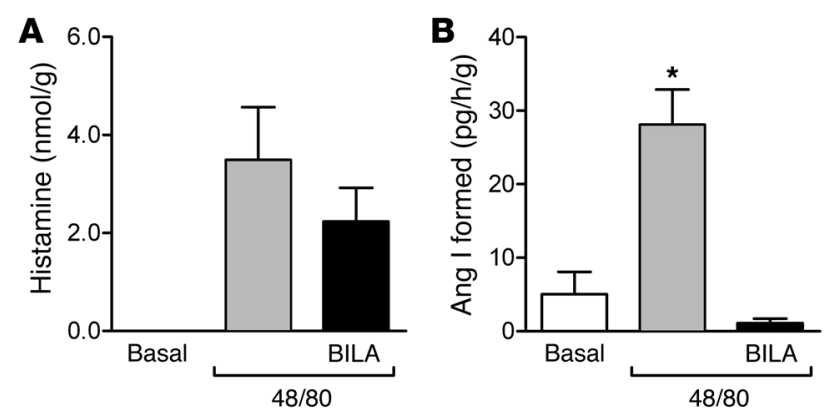

\section{Figure 1}

Coronary overflow of active renin (i.e., Ang I formed) and histamine from Langendorff-perfused guinea pig hearts challenged with the mast cell-degranulating compound 48/80 (300 $\mu \mathrm{g})$ either in the absence or presence of the renin inhibitor BILA2157 (BILA; $100 \mathrm{nM}$ ). Bars indicate means \pm SEM of overflow collected over 6 minutes either before (basal) or immediately following the administration of $48 / 80$. (A) $n=7,4$, and 3 , respectively; (B) $n=6,3$, and 3 , respectively. *Significantly different from both basal and BILA2157-treated hearts. $P<0.05$ by 1 -way ANOVA with Dunnett's procedure. Neither basal nor BILA2157-treated hearts were significantly different from 0 (1-sample Student's $t$ test).

BILA2157 (100 nM) (21) prior to 48/80 challenge, Ang I-forming activity in the coronary effluent was abolished (Figure 1B), indicating that the Ang I was most likely entirely formed by renin and not by another Ang I-forming enzyme, e.g., cathepsin D, a protease that can convert angiotensinogen to Ang I, but at a rate $10^{5}$ times slower than renin (22), and that is 200 times less sensitive than renin to BILA2157 (21). To verify the mast cell-degranulating action of compound $48 / 80$, we also assayed histamine overflow in the guinea pig hearts. As shown in Figure 1A, coronary overflow of histamine increased from a nonmeasurable level to approximately $4 \mathrm{nmol} / \mathrm{g}$ with compound 48/80. BILA2157 did not significantly affect histamine overflow. These results establish that cardiac mast cells release active renin upon degranulation.

We next ascertained whether mast cell-derived renin can activate a local RAS, leading to Ang II formation and potentiation of NE release. For this, we first measured NE release directly in sympathetic nerve endings (i.e., cardiac synaptosomes). Synaptosomes were isolated from control guinea pig hearts and incubated with angiotensinogen. As shown in Figure 2A, NE release from synaptosomes increased directly with the concentration of angiotensinogen in the incubation medium (i.e., NE release increased by 10, 20, and $30 \%$ with $2.4,24$, and $240 \mathrm{nM}$ angiotensinogen, respectively).
Notably, when hearts were challenged with 48/80 (300 $\mu \mathrm{g}$ bolus) prior to isolation of synaptosomes, angiotensinogen-induced NE release was potentiated, whereas it was markedly attenuated when hearts were perfused with the mast cell stabilizer lodoxamide (10 $\mu \mathrm{M}$ ) for 20 minutes (23) prior to challenge with 48/80 (see Figure $2 \mathrm{~A}$ ). Importantly, the potentiating effect of $48 / 80$ was abolished when synaptosomes were incubated with the renin inhibitor BILA2157 (10 nM; Figure 2B). When synaptosomes isolated from hearts perfused with lodoxamide prior to $48 / 80$ challenge were incubated with BILA2157, angiotensinogen failed to affect NE release (Figure 2B). Similarly, the angiotensinogen-dependent release of NE was also blocked when synaptosomes from 48/80pretreated hearts were incubated with the angiotensin-converting enzyme (ACE) inhibitor enalaprilat $(30 \mathrm{nM})(24)$ or the $\mathrm{AT}_{1}$ receptor antagonist EXP3174 $(10 \mathrm{nM})(25,26)$ (Figure $2 \mathrm{C})$. These findings suggest that renin derived from cardiac mast cells is capable of initiating local formation of Ang II, which then elicits the release of NE from cardiac sympathetic nerves.

To determine which receptor subtype mediates the NE-releasing effect of Ang II, cardiac synaptosomes isolated from control guinea pig hearts were challenged with Ang II either in control conditions or in the presence of EXP3174 $\left(10 \mathrm{nM} ; \mathrm{K}_{\mathrm{i}}\right.$ [concentration at which half-maximum effect is obtained] $10 \mathrm{nM})(25)$ or the $\mathrm{AT}_{2}$ receptor antagonist PD123,319 (100 nM; $\left.\mathrm{K}_{\mathrm{i}}, 5 \mathrm{nM}\right)(27)$. As shown in Figure 3 , in the $0.1-100 \mathrm{nM}$ range, Ang II caused a concentration-dependent $(-10-40 \%)$ increase in NE release above basal level. The selective $\mathrm{AT}_{1}$ receptor antagonist EXP3174 $(10 \mathrm{nM})$ shifted the Ang II concentration-response curve downwards. In contrast, the $\mathrm{AT}_{2}$ receptor antagonist PD123,319 failed to modify the NE-releasing effect of Ang II; this revealed the involvement of $\mathrm{AT}_{1}$ but not $\mathrm{AT}_{2}$ receptors.

Ischemia/reperfusion in guinea pig hearts, release of mast cell renin and NE overflow: relation to reperfusion arrhythmias. In order to test our hypothesis that release of mast cell-derived renin in response to ischemia/reperfusion leads to Ang II formation, excessive NE release, and reperfusion arrhythmias, we performed the following experiments. Two species and 2 ischemia/reperfusion models were used. First, ex vivo, Langendorff-perfused guinea pig hearts were subjected to 20 minutes of stop-flow global ischemia, followed by 30 minutes of reperfusion (28). The overflow of active renin (i.e., Ang I formed) during reperfusion was approximately 6-fold greater than preischemia level (Figure 4C), while NE overflow was approximately 70-fold greater (Figure 4B). Reperfusion was also associated with ventricular arrhythmias, such as ventricular tachycardia (VT) and ventricular fibrillation (VF) (Figures 4A and 5); these rhythm disturbances had a $100 \%$ incidence (Figure 5A) and

\section{Figure 2}

Release of NE from guinea pig heart synaptosomes incubated with human angiotensinogen (2.4-240 nM). (A) Prior to synaptosome isolation, hearts were untreated (control) or challenged with compound 48/80 (300 $\mu \mathrm{g}$, bolus injection) preceded or not by lodoxamide $(10 \mu \mathrm{M})$. Synaptosomes were incubated with BILA2157 (10 nM) (B), enalaprilat (ENAL, $30 \mathrm{nM})$, or EXP3174 (EXP, $10 \mathrm{nM})(\mathrm{C})$. Data points indicate means ( \pm SEM) of amount of NE released expressed as $\mathrm{pmol} / \mathrm{mg}$ protein $(n=4$; in each panel, the 0 point on the abscissa indicates basal NE release). For reference, the control curve shown in $\mathbf{A}$ is repeated in $\mathbf{B}$, and the $48 / 80$ curve shown in $\mathbf{A}$ is repeated in $\mathbf{B}$ and $\mathbf{C}$.

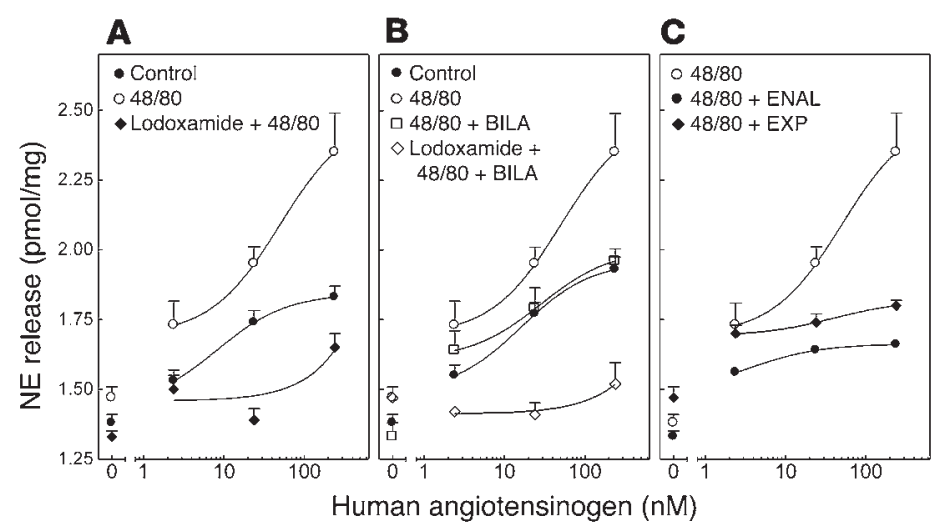




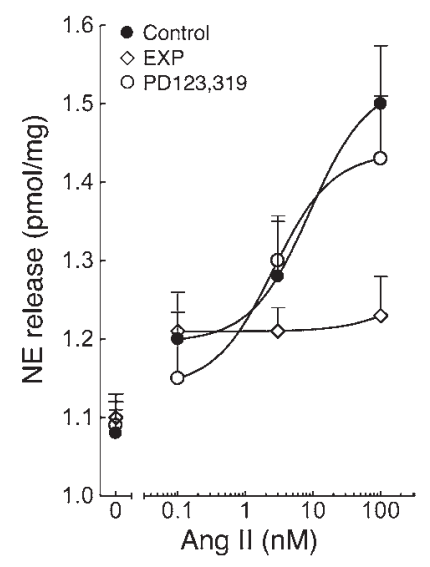

Figure 3

The administration of exogenous Ang II elicits NE release from guinea pig heart synaptosomes. The effect of Ang II is attenuated by EXP3174 (10 $\mathrm{nM}$ ) but not by PD123,319 (100 nM). Data points indicate means \pm SEM of amount of NE released expressed as $\mathrm{pmol} / \mathrm{mg}$ protein $(n=8)$. The zero point on the abscissa indicates basal NE release.

lasted an average of approximately 320 seconds (Figure 4A). Notably, overflow of Ang I-forming activity was reduced by approximately $60-70 \%$ when hearts were perfused with lodoxamide $(10 \mu \mathrm{M})$ or cromolyn $(300 \mu \mathrm{M})$ and by approximately $90 \%$ with BILA2157 (100 nM); in fact, overflow of Ang I-forming activity in the presence of BILA2157 was not significantly different from the preischemia value (Figure 4C). As expected, perfusion with the $\mathrm{AT}_{1}$ receptor antagonist EXP3174 $(300 \mathrm{nM})$ did not significantly reduce the overflow of Ang I-forming activity (Figure 4C) since this compound acts downstream of renin release. Lodoxamide, cromolyn, BILA2157, and EXP3174 each reduced NE overflow by approximately 40, 30, 60, and 70\%, respectively, (Figure 4B), suggesting that Ang II formed by RAS activation, initiated by mast cell-derived renin, elicited NE release via $\mathrm{AT}_{1}$ receptor activation (Figure 4B). Moreover, lodoxamide, cromolyn, BILA2157, and EXP3174 each markedly decreased the incidence of reperfusion arrhythmias (from $100 \%$ to $\sim 50,30,30$, and $40 \%$, respectively); when arrhythmias occurred, their duration was abbreviated by approximately $85,95,90$, and 90\%, respectively (Figures 4A and $5)$. These results are consistent with our hypothesis that release of mast cell-derived renin in ischemia/reperfusion is the pivotal trigger for local cardiac RAS activation and can result in arrhythmias. To test this model further, we looked at mast cell release of renin in an ischemia/reperfusion mouse model.

\section{Figure 4}

Ischemia/reperfusion in isolated guinea pig hearts elicits the release of mast cell renin, Ang II formation, NE release, and reperfusion arrhythmias. Fifty-five guinea pig hearts were subjected to 20-minute global ischemia followed by 30 -minute reperfusion either in the absence $(n=15)$ or presence of lodoxamide (Lodox, $10 \mu \mathrm{M} ; n=13$ ), cromolyn (Crom, $300 \mu \mathrm{M} ; n=11$ ), BILA2157 (BILA, $100 \mathrm{nM} ; n=6$ ), or EXP3174 (EXP, $300 \mathrm{nM} ; n=10)$. Bars indicate means \pm SEM. (A) Duration of reperfusion arrhythmias (VT/VF). (B and C) Overflow of NE and Ang Iforming activity collected over 6 minutes either before ischemia or at the start of reperfusion. *Significantly different from own control; $P<0.05$ by 1 -way ANOVA with Dunnett's procedure.
Ischemia/reperfusion in mouse hearts, release of mast cell renin and NE overflow: relation to reperfusion arrbythmias. Ex vivo, Langendorffperfused mouse hearts were subjected to 20 minutes of ischemia induced by a 20 -minute perfusion with glucose- and pyruvic acidfree Krebs-Henseleit $(\mathrm{KH})$ buffer equilibrated with $95 \% \mathrm{~N}_{2}$ and $5 \%$ $\mathrm{CO}_{2}$ and containing the reducing agent sodium dithionite $(0.25$ $\mathrm{mM}$ ), followed by 30 minutes of reperfusion with oxygenated $\mathrm{KH}$ buffer (29). The overflow of Ang I-forming activity during reperfusion was approximately 5 -fold greater than the preischemia level (Figure 6C) while NE overflow was approximately 150 -fold greater (Figure 6B). Reperfusion was also associated with VT and VF (Figures $6 \mathrm{~A}$ and 7); these rhythm disturbances had a $100 \%$ incidence (Figure 7) and lasted an average of approximately 260 seconds (Figure 6A). The overflow of Ang I-forming activity was reduced by approximately $95 \%$ when hearts were perfused with cromolyn (300 $\mu \mathrm{M})$ and by approximately $60 \%$ with BILA2157 (100 nM) (Figure $6 C)$. With cromolyn and BILA2157, NE overflow was also reduced by approximately 70 and 50\%, respectively (Figure 6B). Moreover, cromolyn reduced the incidence of reperfusion arrhythmias (from 100 to $50 \%$ ) and abbreviated their duration by $97 \%$ while BILA 2157 abolished them altogether (Figures 6A and 7). These results, like those in the guinea pig experiments, demonstrate that renin released from cardiac mast cells in ischemia/reperfusion sets forth a local RAS leading to arrhythmias. We next pursued ischemia/ reperfusion experiments in mast cell-deficient mouse hearts.

Ischemia/reperfusion in mast cell-deficient mouse hearts: marked reduction in renin overflow and reperfusion arrbythmias. Inasmuch as our experiments in both guinea pigs and mice suggested that mast

$\mathbf{A}$

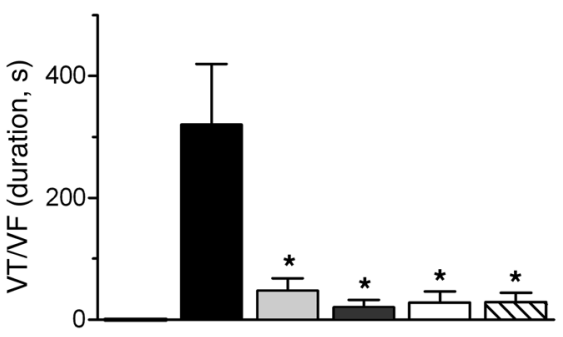

B

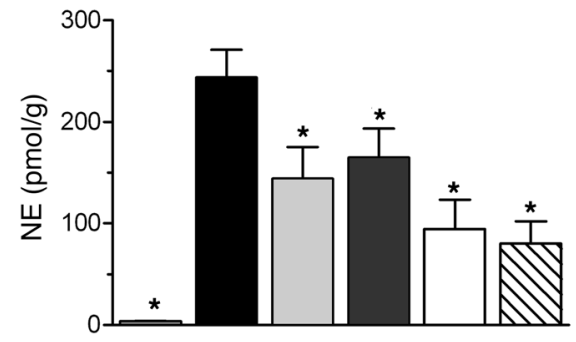

C

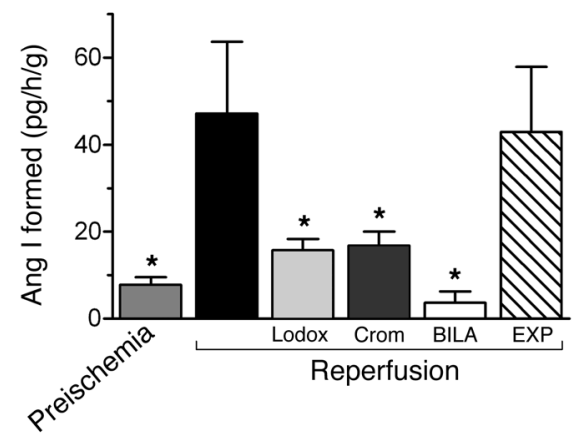


A

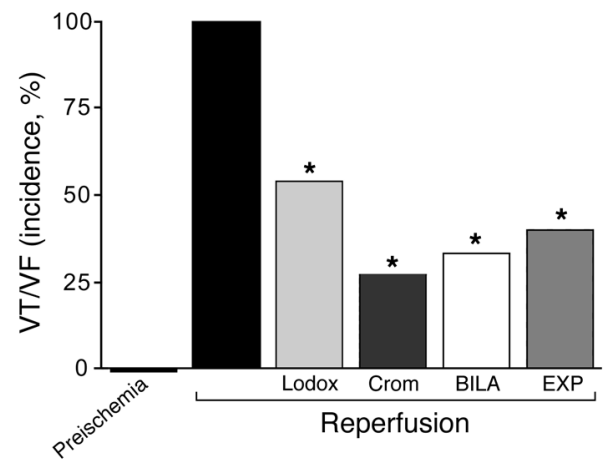

B

Before ischemia
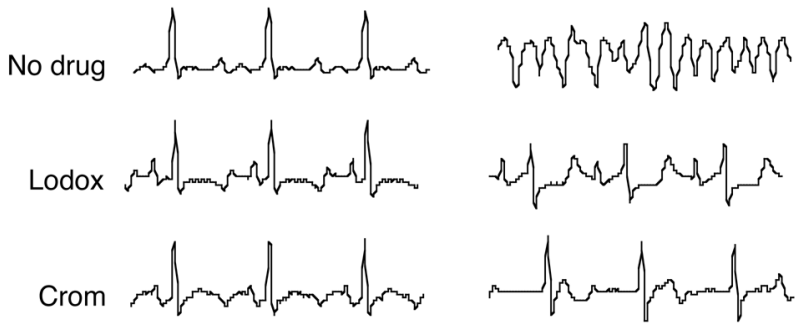

BILA

EXP
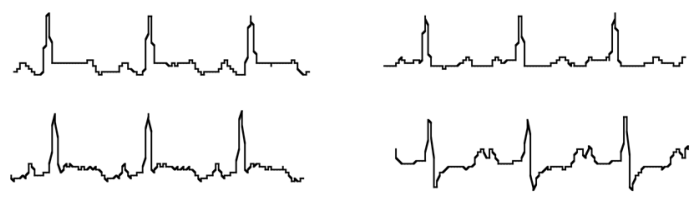

cell-derived renin is pivotal for local RAS activation, culminating in reperfusion arrhythmias, we sought a further proof in hearts of $\mathrm{WBB} 6 \mathrm{~F}_{1}-\mathrm{W} / \mathrm{W}^{\mathrm{v}}$ mice, which are known to be mast cell free (30). Given that conjugated avidin selectively binds to mast cell granules (31), fixed and frozen sections of mouse hearts were screened for avidin- and renin-positive mast cells. Representative images of sections from control and mast cell-deficient mouse hearts are shown in Figure 8. As predicted, in control hearts, the avidin-positive mast cell population was also immunopositive for renin. No other cells stained with FITC-avidin or renin antibody; there was no immunoreactivity when sections were incubated with nonimmune rabbit serum. No mast cells were detected in any of the mast cell-deficient mouse heart sections screened.

Ex vivo, Langendorff-perfused mast cell-deficient mouse hearts were subjected to 20 -minute ischemia (glucose- and pyruvic acidfree $\mathrm{KH}$ buffer, $95 \% \mathrm{~N}_{2}+5 \% \mathrm{CO}_{2}$, and sodium dithionite) followed

\section{Figure 6}

The release of mast cell renin in isolated mouse hearts subjected to ischemia/reperfusion is associated with NE release and reperfusion arrhythmias. Nineteen mouse hearts were subjected to 20-minute ischemia (i.e., perfusion with glucose- and pyruvic acid-free $\mathrm{KH}$ buffer bubbled with $95 \% \mathrm{~N}_{2}+5 \% \mathrm{CO}_{2}$ ) followed by a 30 -minute reperfusion with oxygenated $\mathrm{KH}$ buffer, either in the absence $(n=7)$ or presence of cromolyn ( $300 \mu \mathrm{M} ; n=6)$ or BILA2157 (100 nM; $n=6)$. Bars indicate means \pm SEM. (A) Duration of reperfusion arrhythmias (VT/VF). Note that reperfusion arrhythmias were prevented in hearts pretreated with BILA2157. (B and C) Overflow of NE and Ang I-forming activity collected over 30 minutes either before ischemia or at the start of reperfusion. *Significantly different from own control; $P<0.05$ by 1 -way ANOVA with Dunnett's procedure.

\section{Figure 5}

Mast cell stabilization, renin inhibition, and $\mathrm{AT}_{1}$ receptor blockade markedly reduce the occurrence of reperfusion arrhythmias in a guinea pig heart model of ischemia/reperfusion. (A) Percentage incidence of VT/VF in 55 hearts subjected to 20-minute global ischemia followed by 30 -minute reperfusion either in the absence $(n=15)$ or presence of lodoxamide (10 $\mu \mathrm{M} ; n=13)$, cromolyn (300 $\mu \mathrm{M} ; n=11)$, BILA2157 (100 nM; $n=6)$, or EXP3174 (300 nM; $n=10)$. *Significantly different from control reperfusion; $P<0.05$ by $\chi^{2}$ test. (B) Representative ECG tracings from 5 of the above hearts.

by 30-minute reperfusion with oxygenated KH buffer. Compared with control mouse hearts, mast cell-deficient hearts released $50 \%$ less Ang I-forming activity (670 \pm 121 versus $1349 \pm 275 \mathrm{pg} /$ $\mathrm{h} / \mathrm{g} ; n=7+7 ; P<0.001$ by 2 -tailed unpaired Student's $t$ test). Furthermore, reperfusion arrhythmias lasted only an average of $18 \pm 10$ seconds as compared with $246 \pm 122$ seconds in control hearts (i.e., a $93 \%$ decrease; $P<0.005$ ). These findings support the notion that the release of mast cell renin plays a pivotal role in the initiation of a series of events culminating in the generation of reperfusion arrhythmias.

\section{Discussion}

We had previously demonstrated the presence of immunoreactive renin in cardiac mast cells juxtaposed to nerve endings and hypothesized that these cells are a crucial component of a unique extrarenal RAS in the heart (11). The major finding of the present study is that, with degranulation, cardiac mast cells release significant amounts of renin. We demonstrated this with classical mast cell-degranulating agents and, more importantly, in a model of ischemia/reperfusion. A consequence of this local release of renin is formation of Ang II in the vicinity of cardiac sympathetic nerve

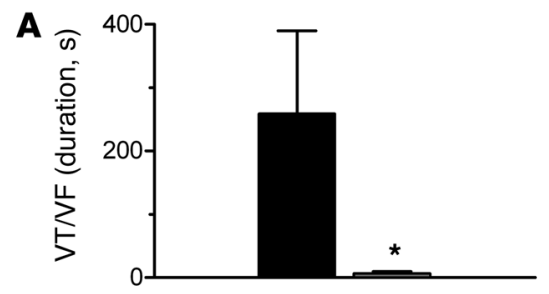

B
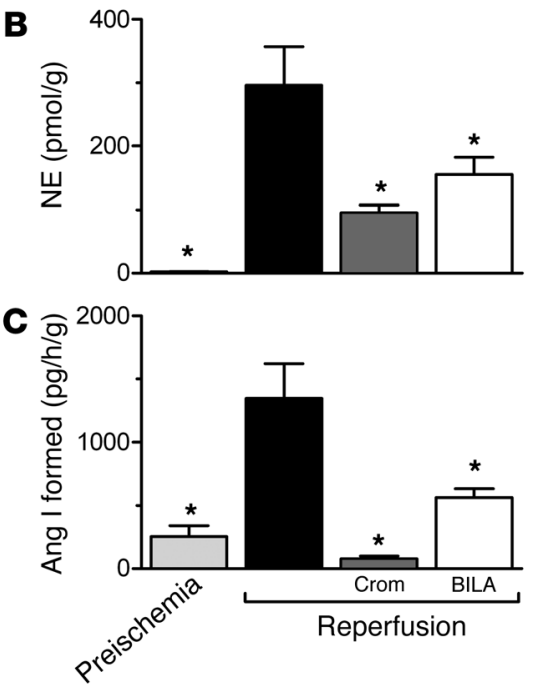
A

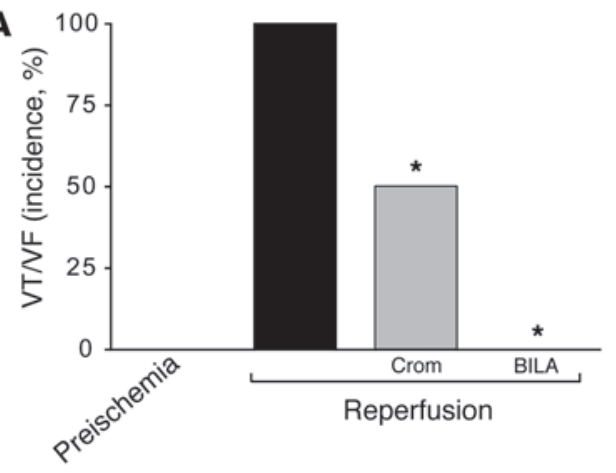

B

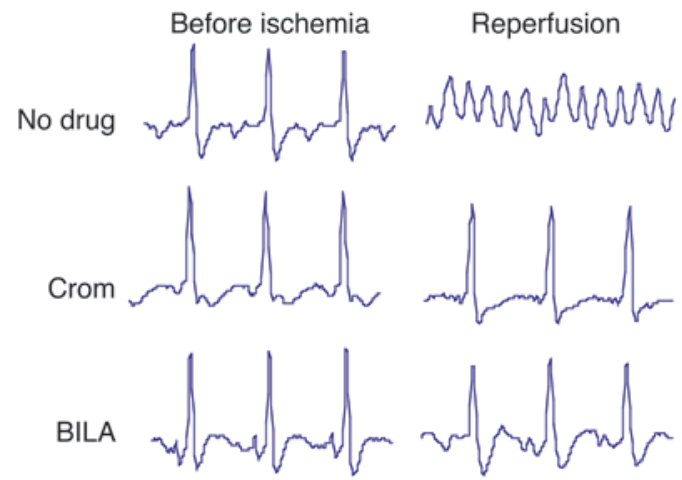

C

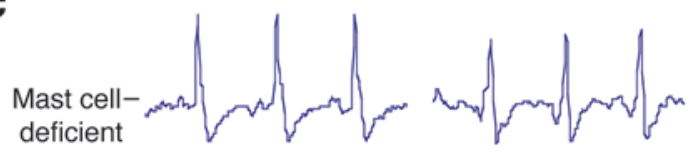

endings expressing $\mathrm{AT}_{1}$ receptors $(15,16)$. This then leads to augmented NE release and arrhythmic dysfunction. Mast cell stabilizing agents prevented these deleterious events, confirming a pivotal role of mast cell-derived renin in this cascade.

The role of sympathetic nerve endings in response to the release of mast cell-derived renin was confirmed in our studies on cardiac synaptosomes. This in vitro assay clearly indicates that $\mathrm{AT}_{1}$ receptor activation by locally produced Ang II leads to enhanced release of NE. As shown in our isolated-heart studies, this augmented NE release can be deleterious by leading to arrhythmias.

Having demonstrated that renin derived from cardiac mast cells is capable of driving Ang II formation, which leads to potentiation of $\mathrm{NE}$ release from cardiac nerves, we assessed whether a similar process may play a role in myocardial ischemia. Indeed, mast cell degranulation is known to occur in myocardial ischemia, with C5a, adenosine, and reactive oxygen species as likely mediators $(17,18,32)$. Following global ischemia in isolated guinea pig hearts, reperfusion was associated with the overflow of Ang I-forming activity and NE and with the development of reperfusion arrhythmias, such as VT and VF. Most likely, this Ang I was formed entirely by renin since it was abolished by the specific renin inhibitor BILA2157 (21). Notably, the overflow of Ang Iforming activity was markedly reduced by cromolyn or lodoxamide, 2 well-known mast cell stabilizers $(23,33)$. This indicates that mast cell-derived renin is respon-

\section{Figure 7}

Mast cell stabilization and renin inhibition markedly reduce the occurrence of reperfusion arrhythmias in a mouse heart model of ischemia/ reperfusion. (A) Percentage incidence of VT/VF in 19 hearts subjected to 20-minute ischemia (i.e., perfusion with glucose- and pyruvic acid-free $\mathrm{KH}$ buffer bubbled with $95 \% \mathrm{~N}_{2}+5 \% \mathrm{CO}_{2}$ ) followed by a 30-minute reperfusion with oxygenated $\mathrm{KH}$ buffer either in the absence $(n=7)$ or presence of cromolyn $(300 \mu \mathrm{M} ; n=6)$ or BILA2157 $(100 \mathrm{nM}$; $n=6)$. * Significantly different from control reperfusion; $P<0.05$ by $\chi^{2}$ test. (B) Representative ECG tracings from 3 of the above hearts. (C) Representative ECG tracings from 1 mast cell-deficient mouse heart recorded before ischemia and during reperfusion.

sible for the Ang I-forming activity released during ischemia/ reperfusion. Moreover, mast cell stabilization, renin inhibition, and $\mathrm{AT}_{1}$ receptor blockade all reduced $\mathrm{NE}$ release and practically eliminated reperfusion arrhythmias. This demonstrates that ischemia/reperfusion promotes the release of active renin from cardiac mast cells, thus initiating local Ang II formation and an $\mathrm{AT}_{1}$ receptor-mediated increase in the magnitude of $\mathrm{NE}$ release and the severity of arrhythmias. It is conceivable that Ang II contributed to reperfusion arrhythmias not only by facilitating NE release $(15,34-36)$ but also by its direct arrhythmogenic action $(37,38)$. Further, although mast cell stabilization, renin inhibition, and $\mathrm{AT}_{1}$ receptor blockade inhibited NE release, this inhibition was not complete. Indeed, in addition to Ang II, other mediators, such as bradykinin, adenosine triphosphate (ATP), and tissue-plasminogen activator, are likely to contribute to NE release in myocardial ischemia and reperfusion $(28,39,40)$.

Since our evidence in the guinea pig pointed to mast cells as the pivotal source of renin released from the heart during ischemia/ reperfusion, we chose to substantiate this finding in an additional model. Similar to the guinea pig, Langendorff-perfused control WBB $6 \mathrm{~F}_{1^{-+/+}}$mouse hearts subjected to ischemia/reperfusion released considerable amounts of renin and NE in association with VT and VF. Again, mast cell stabilization and renin inhibition each markedly reduced the overflow of Ang I-forming activity and NE and abolished reperfusion arrhythmias. These findings strengthen

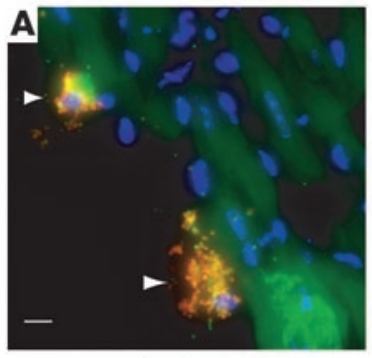

Control

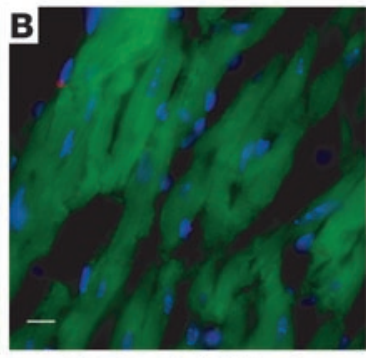

Mast cell-deficient

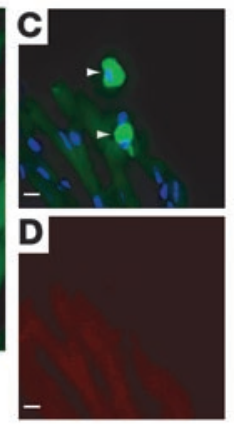

\section{Figure 8}

Identification of renin-positive mast cells in mouse heart sections. (A) Representative section of control mouse heart stained with the polyclonal anti-renin antibody (red), FITC-avidin (green) to identify mast cells (arrowheads), and DAPI (blue) to visualize nuclei. (B) Section of mast cell-deficient mouse heart stained with the polyclonal anti-renin antibody, FITC-avidin, and DAPI. No mast cells were detected in any of the mast cell-deficient mouse heart sections screened. (C and D) Control mouse heart section incubated with nonimmune rabbit serum. In C, mast cells are visualized by FITC-avidin and DAPI staining. In D, mast cells do not react with the nonimmune rabbit serum. Magnification, $\times 60$. Scale bars: $10 \mu \mathrm{m}$. 


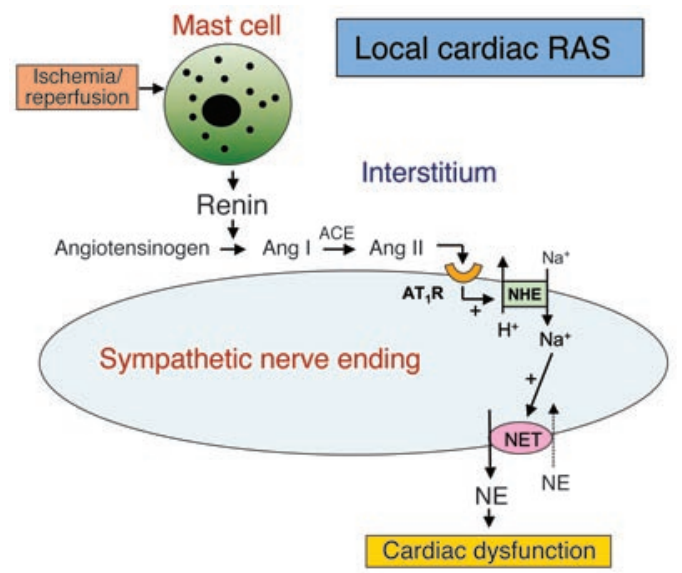

Figure 9

Model of local cardiac RAS and its activation in myocardial ischemia. $A T_{1} R, A_{1}$ receptor; $\mathrm{NHE}, \mathrm{Na}^{+} / \mathrm{H}^{+}$exchanger; $\mathrm{NET}$, NE transporter.

the notion that the release of mast cell-derived renin in ischemia/ reperfusion activates a local RAS, leading to severe arrhythmias.

The overflow of Ang I-forming activity from mouse hearts during reperfusion was approximately 5 -fold greater than that from guinea pig hearts. This might reflect differences in cardiac mast cell number or mast cell phenotype between the 2 species. Guinea pig and mouse hearts also differed in that Ang I-forming activity was completely blocked by mast cell stabilization in the mouse, as compared with a $60-70 \%$ inhibition in the guinea pig. In addition, renin inhibition was completely effective in the guinea pig, as compared with a $60 \%$ inhibition in the mouse. This suggests that in the guinea pig heart, Ang I-forming activity is entirely attributable to renin derived principally from mast cells, with only a minor contribution from other sources. In the mouse, Ang I-forming activity appears to be entirely mast cell derived, but other nonrenin mast cell-derived Ang I-forming enzymes could also be involved.

Inasmuch as mast cell stabilization was very effective in inhibiting renin release and arrhythmias in the mouse heart during reperfusion, we reasoned that renin release and arrhythmias would also be reduced in the absence of mast cells. For this, we used the mast cell-deficient $\mathrm{WBB} \mathrm{F}_{1}-\mathrm{W} / \mathrm{WW}^{\mathrm{v}}$ mouse (41). Whereas control $\mathrm{WBB} \mathrm{F}_{1^{-}}{ }^{+/+}$mouse hearts displayed renin immunoreactivity exclusively in mast cells, neither mast cells nor renin were detected by immunohistochemistry in any of the mast cell-deficient heart sections screened. Indeed, mast cell-deficient hearts subjected to ischemia/reperfusion released much less Ang I-forming activity than control hearts. Most importantly, mast cell-deficient hearts had no reperfusion arrhythmias. We did not attempt to reverse these changes by mast cell reconstitution since cardiac mast cells, unlike lung mast cells, cannot be reconstituted by transfusion of bone marrowderived mast cells (42). Yet, the fact that mast cell-deficient and mast cell-stabilized hearts behaved similarly in terms of renin release and reperfusion arrhythmias strengthens the notion that the release of mast cell-derived renin is a critical event in ischemia/reperfusion.

In conclusion, we present evidence in support of our hypothesis that cardiac mast cells contain renin that, once released, initiates the activation of a local RAS. Based on our present and previous results $(11,16)$, we postulate that mast cell degranulation, as occurs in myocardial ischemia, releases active renin into the interstitium, where renin comes in contact with angiotensinogen $(43,44)$, cleav- ing it to Ang I. Ang I is then converted to Ang II by interstitial ACE (44). The resultant Ang II then interacts with $\mathrm{AT}_{1}$ receptors present on the nerves. Ang II activation of $\mathrm{AT}_{1}$ receptors potentiates $\mathrm{Na}^{+} / \mathrm{H}^{+}$exchanger activity (16), and this serves to increase intraneuronal $\mathrm{Na}^{+}$to a level that triggers excessive carrier-mediated $\mathrm{NE}$ release (45). According to our model, mast cell degranulation is a pivotal event in the activation of a cardiac RAS, leading to excessive release of NE (see Figure 9). Hence, our findings imply that mast cell-derived renin may be a useful therapeutic target for cardiac dysfunctions associated with adrenergic hyperactivity, such as arrhythmias, sudden cardiac death, myocardial ischemia and infarction, cardiac hypertrophy, and congestive heart failure (46-50).

\section{Methods}

Perfusion of guinea pig hearts ex vivo. All experiments were approved by the Institutional Animal Care and Use Committee of Weill Medical College of Cornell University. Male Hartley guinea pigs (Charles River Laboratories) weighing 300-350 grams were anesthetized with $\mathrm{CO}_{2}$ and euthanized by exsanguination. Hearts were rapidly isolated and perfused at constant pressure $\left(40 \mathrm{~cm} \mathrm{H}_{2} \mathrm{O}\right)$ with oxygenated Ringer's solution at $37^{\circ} \mathrm{C}$ for 30 minutes prior to challenge with compound $48 / 80$ or induction of ischemia in a Langendorff apparatus (Radnoti Glass Technology Inc.) (51). In some cases, hearts were continuously perfused with pharmacologic agents (i.e., lodoxamide, cromolyn, BILA2157, enalaprilat, and EXP3174) prior to and during challenge with $48 / 80$ or induction of ischemia/reperfusion. Twenty minutes of normothermic global ischemia was induced by complete cessation of coronary perfusion, followed by 30 minutes of reperfusion. Coronary flow was measured by timed collections of the effluent every 2 minutes; all samples were assayed for renin and NE and some for histamine. Surface ECG was obtained from leads attached to the left ventricle and the right atrium, recorded in both analog and digital format, and analyzed using PowerLab/8SP (ADInstruments). Onset and duration of reperfusion arrhythmias were recorded and quantified according to the Lambeth Conventions (52).

Perfusion of mouse hearts ex vivo. Following pretreatment with heparin (100 IU i.p.), mice (mast cell-deficient $\mathrm{WBB} 6 \mathrm{~F}_{1}-\mathrm{W} / \mathrm{WW}^{\mathrm{v}}$ and their controls, WBB $6 \mathrm{~F}_{1^{-}}+/^{+}$, purchased from Jackson Laboratory; 20-30 g) were anesthetized with $\mathrm{CO}_{2}$ and euthanized by cervical dislocation (Institutional Animal Care and Use Committee approved). Hearts were quickly excised and cooled in ice-cold $\mathrm{KH}$ buffer containing pyruvic acid $(0.5 \mathrm{mM})$ and equilibrated with $95 \% \mathrm{O}_{2}$ plus $5 \% \mathrm{CO}_{2}$, as previously described (29). The aorta was cannulated with a 20-gauge custom-made steel cannula, and the heart was perfused in a Langendorff apparatus (see above) (pressure: $100 \mathrm{~cm}$ $\mathrm{H}_{2} \mathrm{O}$ ) with $\mathrm{KH}$ buffer at $37^{\circ} \mathrm{C}$. Coronary flow was measured by timed collections of the effluent every 5 minutes; all samples were assayed for renin and some for NE. Following stabilization, normothermic global ischemia was induced by perfusing hearts for 20 minutes with glucose- and pyruvic acid-free $\mathrm{KH}$ buffer equilibrated with $95 \% \mathrm{~N}_{2}$ and $5 \% \mathrm{CO}_{2}$ and containing the reducing agent sodium dithionite $(0.25 \mathrm{mM})$, followed by 30 minutes reperfusion with normal $\mathrm{KH}$ buffer (29).

Preparation of cardiac synaptosomes. Guinea pigs (see above) were anesthetized with $\mathrm{CO}_{2}$ and exsanguinated. The rib cage was rapidly opened and the heart dissected away. A cannula was inserted in the aorta, and the heart was perfused at constant pressure $\left(40 \mathrm{~cm} \mathrm{H}_{2} \mathrm{O}\right)$ in a Langendorff apparatus with oxygenated Ringer's solution (53). In the experiments depicted in Figure 2, hearts were challenged with an intraaortic bolus injection of compound 48/80 (300 $\mu \mathrm{g})$ while being perfused with normal Ringer's or with Ringer's containing lodoxamide $(10 \mu \mathrm{M})$. Hearts were subsequently freed from fat and connective tissue and minced in ice-cold $0.32 \mathrm{M}$ sucrose containing 1 mM EGTA, pH 7.4. Synaptosomes (pinched-off sympathetic nerve end- 
ings) were isolated as previously described (53) and incubated with human angiotensinogen $(2.4-240 \mathrm{nM})$ in a water bath at $37^{\circ} \mathrm{C}$ either in the absence or presence of BILA2157 (10 nM), enalaprilat (30 nM), or EXP3174 (10 nM). Controls were incubated for an equivalent length of time without angiotensinogen. At the end of the incubation period, each sample was centrifuged at $20,000 \mathrm{~g}$ for 20 minutes at $4^{\circ} \mathrm{C}$. The supernatant was assayed for $\mathrm{NE}$ content and the pellet for protein content by a modified Lowry procedure (54). In the experiments depicted in Figure 3, synaptosomes were incubated with Ang II (0.1-100 nM for 20 minutes) either in control conditions or in the presence of EXP3174 (10 nM) or PD123,319 (100 nM).

Immunohistochemistry of cardiac mast cells. Cryostat sections $(10 \mu \mathrm{m})$ of paraformaldehyde-fixed heart from either control or mast cell-deficient mice were triple-stained with a rabbit polyclonal anti-renin antibody, FITCavidin, to identify mast cells, and DAPI, to visualize nuclei. Briefly, sections from control or mast cell-deficient mouse hearts were rinsed in PBS and then permeabilized for 10 minutes at $37^{\circ} \mathrm{C}$ with a solution containing $4 \%$ FBS and $0.3 \%$ Triton X-100 dissolved in PBS. Next, 10\% FBS was applied to the sections for 1.5 hours at $37^{\circ} \mathrm{C}$ prior to addition of antibodies. The polyclonal anti-renin antibody (1:400) was applied to the sections for 2 hours at $37^{\circ} \mathrm{C}$, followed by 3 washes in PBS. Next, sections were exposed to Alexa Fluor 594 donkey anti-rabbit IgG (red; Invitrogen Corp.) $(1: 1,100)$ and FITC-avidin (green) $(1: 1,300)$ for 1 hour at $37^{\circ} \mathrm{C}$. Following 3 washes, the sections were incubated with a 1:10,000 dilution of DAPI (blue) for 3 minutes at room temperature. Sections were washed and then fixed for 3 minutes with $4 \%$ paraformaldehyde. Finally, the sections were mounted in Vectashield antifading solution (Vector Laboratories). Mast cells were identified as cells that were triple stained (i.e., renin, FITC-avidin, and DAPI positive). For both control and mast cell-deficient mice, multiple complete heart sections were screened. As a negative control, sections of control mouse hearts were incubated with nonimmune rabbit serum (1:400) instead of the polyclonal anti-renin antibody. The rabbit polyclonal antirenin antibody was kindly provided by Daniel F. Catanzaro (Weill-Cornell Medical Center, New York, New York, USA). FITC-avidin and DAPI were purchased from Vector Laboratories and Invitrogen Corp., respectively. Heart sections were examined with an inverted epifluorescence microscope (Nikon Eclipse TE 2000-U) interfaced to an electron multiplying charged coupled device (Hamamatsu) and processed with Metamorph software (version 6.2; Universal Imaging Corp.). Digital images were imported into Photoshop 7.0 (Adobe Systems Inc.).

$N E$ assay. Coronary effluent and synaptosomal supernatant were assayed for NE by HPLC with electrochemical detection as previously described (53). The detection limit was approximately 0.2 pmol.

Renin assay. Coronary effluent was immediately concentrated 6- to 8-fold by centrifugal filtration (Millipore). Concentrated samples were incubated overnight with human or porcine angiotensinogen $(240 \mathrm{nM})$ for guinea pig and mouse experiments, respectively. Renin activity (Ang I formed) was determined by GammaCoat Plasma Renin Activity ${ }^{125}$ I Radioimmunoassay (DiaSorin). The detection limit was approximately $0.01 \mathrm{pmol}$.

Histamine assay. Coronary effluent was assayed for histamine content with the use of a commercial enzyme immunoassay kit (Immunotech International) (55). The recovery of histamine was approximately $100 \%$, and the detection limit was approximately $0.02 \mathrm{pmol}$.

Drugs and chemicals. BILA2157 was a gift from Boehringer Ingelheim; enalaprilat and EXP3174 were gifts from Merck, Sharpe, and Dohme Ltd.; lodoxamide was a gift from B.R. Lucchesi, University of Michigan, Ann Arbor, Michigan, USA; compound 48/80, cromolyn, and PD123,319 were purchased from Sigma-Aldrich. BILA2167 and EXP3174 were dissolved in DMSO and ethanol, respectively, with further dilutions in the appropriate buffer; at the concentration used, DMSO and ethanol did not affect mediator release. Human plasma angiotensinogen was purchased from Calbiochem. Porcine plasma angiotensinogen and Ang II were purchased from Sigma-Aldrich.

Statistics. One-way ANOVA followed by Dunnett's procedure, 1-sample Student's $t$ test, and 2-tailed unpaired Student's $t$ test were used where appropriate, as indicated in the figure legends. $P<0.05$ was considered significant.

\section{Acknowledgments}

These studies were supported by NIH grants HL73400, HL34215, HL46403, HL47073, and DK60726 and Minority Access to Research Careers grant GM64875.

Address correspondence to: Roberto Levi, Weill Medical College of Cornell University, Room LC419, 1300 York Avenue, New York, New York 10021, USA. Phone: (212) 746-6223; Fax: (212) 7468835; E-mail: rlevi@med.cornell.edu.
1. Peach, M.J. 1977. Renin-angiotensin system: biochemistry and mechanisms of action. Physiol. Rev. 57:313-370.

2. Campbell, D.J. 1987. Circulating and tissue angiotensin systems. J. Clin. Invest. 79:1-6.

3. Lindpaintner, K., and Ganten, D. 1991. The cardiac renin-angiotensin system. An appraisal of present experimental and clinical evidence. Circ. Res. 68:905-921.

4. Dinh, D.T., Frauman, A.G., Johnston, C.I., and Fabiani, M.E. 2001. Angiotensin receptors: distribution, signalling and function. Clin. Sci. (Lond.). 100:481-492.

5. Dostal, D.E., and Baker, K.M. 1999. The cardiac renin-angiotensin system: conceptual, or a regulator of cardiac function? Circ. Res. 85:643-650.

6. Bader, M., et al. 2001. Tissue renin-angiotensin systems: new insights from experimental animal models in hypertension research. J. Mol. Med. 79:76-102

7. Dzau, V.J. 1987. Implications of local angiotensin production in cardiovascular physiology and pharmacology. Am. J. Cardiol. 59:59A-65A.

8. Gavras, H., and Brunner, H.R. 2001. Role of angiotensin and its inhibition in hypertension, ischemic heart disease, and heart failure. Hypertension. 37:342-345

9. Berry, C., Touyz, R., Dominiczak, A.F., Webb, R.C., and Johns, D.G. 2001. Angiotensin receptors: sig- naling, vascular pathophysiology, and interactions with ceramide. Am. J. Physiol. Heart Circ. Physiol. 281:H2337-H2365.

10. Jalowy, A., Schulz, R., and Heusch, G. 1999. AT 1 receptor blockade in experimental myocardial ischemia/reperfusion. J. Am. Soc. Nephrol. 10:S129-S136.

11. Silver, R.B., et al. 2004. Mast cells: a unique source of renin. Proc. Natl. Acad. Sci. U. S. A. 101:13607-13612.

12. Barlucchi, L., et al. 2001. Canine ventricular myocytes possess a renin-angiotensin system that is upregulated with heart failure. Circ. Res. 88:298-304.

13. Endo-Mochizuki, Y., et al. 1995. Expression of renin and angiotensin-converting enzyme in human hearts. Heart Vessels. 10:285-293.

14. Passier, R.C., Smits, J.F., Verluyten, M.J., and Daemen, M.J. 1996. Expression and localization of renin and angiotensinogen in rat heart after myocardial infarction. Am. J. Physiol. 271:H1040-H1048.

15. Seyedi, N., Win, T., Lander, H.M., and Levi, R. 1997. Bradykinin $\mathrm{B}_{2}$-receptor activation augments norepinephrine exocytosis from cardiac sympathetic nerve endings. Mediation by autocrine/paracrine mechanisms. Circ. Res. 81:774-784.

16. Reid, A.C., Mackins, C.J., Seyedi, N., Levi, R., and Silver, R.B. 2004. Coupling of angiotensin II $\mathrm{AT}_{1}$ receptors to neuronal NHE activity and carrier-mediated norepinephrine release in myocardial ischemia. Am. J. Physiol. Heart Circ. Physiol. 286:H1448-H1454.
17. Kruger, P.G., Ellingsen, T., and Saetersdal, T.S. 1990. Response of rat myocardial mast cells to experimental ischemia. J. Exp. Pathol. 5:29-38.

18. Frangogiannis, N.G., et al. 1998. Resident cardiac mast cells degranulate and release preformed TNF- $\alpha$, initiating the cytokine cascade in experimental canine myocardial ischemia/reperfusion. Circulation. 98:699-710.

19. Paton, W.D. 1951. Compound 48/80: a potent histamine liberator. Br. J. Pharmacol. 6:499-508.

20. Levi, R., and Allan, G. 1980. Histamine-mediated cardiac effects. In Drug-induced heart disease. M.R. Bristow, editor. Elsevier. New York, New York, USA. 377-395.

21. Simoneau, B., et al. 1999. Discovery of non-peptidic P2-P3 butanediamide renin inhibitors with high oral efficacy. Bioorg. Med. Chem. 7:489-508.

22. Hackenthal, E., Hackenthal, R., and Hilgenfeldt, U. 1978. Isorenin, pseudorenin, cathepsin D and renin. A comparative enzymatic study of angiotensin-forming enzymes. Biochim. Biophys. Acta. 522:574-588.

23. Keller, A.M., Clancy, R.M., Barr, M.L., Marboe, C.C., and Cannon, P.J. 1988. Acute reoxygenation injury in the isolated rat heart: role of resident cardiac mast cells. Circ. Res. 63:1044-1052.

24. Weisser, K., and Schloos, J. 1991. The role of enzyme and substrate concentration in the evaluation of serum angiotensin converting enzyme (ACE) inhi- 
bition by enalaprilat in vitro. Biochem. Pharmacol. 42:1729-1737.

25. Wienen, W., Mauz, A.B., Van Meel, J.C., and Entzeroth, M. 1992. Different types of receptor interaction of peptide and nonpeptide angiotensin II antagonists revealed by receptor binding and functional studies. Mol. Pharmacol. 41:1081-1088.

26. Wong, P.C., et al. 1990. Nonpeptide angiotensin II receptor antagonists. XI. Pharmacology of EXP3174: an active metabolite of DuP 753, an orally active antihypertensive agent. J. Pharmacol. Exp. Ther. 255:211-217.

27. Alexander, S., Mathie, A., Peters, J., MacKenzie, G., and Smith, A. 2001. TiPS nomenclature supplement 2001. 12th edition. Current Trends. London, United Kingdom. 146 pp.

28. Hatta, E., Maruyama, R., Marshall, S.J., Imamura, M., and Levi, R. 1999. Bradykinin promotes ischemic norepinephrine release in guinea pig and human hearts. J. Pharmacol. Exp. Ther. 288:919-927.

29. Koyama, M., Seyedi, N., Fung-Leung, W.P., Lovenberg, T.W., and Levi, R. 2003. Norepinephrine release from the ischemic heart is greatly enhanced in mice lacking histamine $\mathrm{H}_{3}$ receptors. Mol. Pharmacol. 63:378-382.

30. Galli, S.J., and Kitamura, Y. 1987. Genetically mastcell-deficient $\mathrm{W} / \mathrm{Wv}$ and $\mathrm{Sl} / \mathrm{Sld}$ mice. Their value for the analysis of the roles of mast cells in biologic responses in vivo. Am. J. Pathol. 127:191-198.

31. Tharp, M.D., Seelig, L.L., Jr., Tigelaar, R.E., and Bergstresser, P.R. 1985. Conjugated avidin binds to mast cell granules. J. Histochem. Cytochem. 33:27-32.

32. Frangogiannis, N.G., Smith, C.W., and Entman, M.L. 2002. The inflammatory response in myocardial infarction. Cardiovasc. Res. 53:31-47.

33. Theoharides, T.C., Sieghart, W., Greengard, P., and Douglas, W.W. 1980. Antiallergic drug cromolyn may inhibit histamine secretion by regulating phosphorylation of a mast cell protein. Science. 207:80-82.

34. Zimmerman, B.G. 1962. Effect of acute sympathectomy on responses to angiotensin and norepinephrine. Circ. Res. 11:780-787.
35. Schomig, A. 1990. Catecholamines in myocardial ischemia. Systemic and cardiac release. Circulation. 82:II13-II22.

36. Rump, L.C., Schwertfeger, E., Schaible, U., Fraedrich, G., and Schollmeyer, P. 1994. $\beta_{2}$-adrenergic receptor and angiotensin II receptor modulation of sympathetic neurotransmission in human atria. Circ. Res. 74:434-440.

37. Fleetwood, G., Boutinet, S., Meier, M., and Wood, J.M. 1991. Involvement of the renin-angiotensin system in ischemic damage and reperfusion arrhythmias in the isolated perfused rat heart. J. Cardiovasc. Pharmacol. 17:351-356.

38. Cardin, S., et al. 2003. Evolution of the atrial fibrillation substrate in experimental congestive heart failure: angiotensin-dependent and -independent pathways. Cardiovasc. Res. 60:315-325.

39. Sesti, C., Koyama, M., Broekman, M.J., Marcus, A.J., and Levi, R. 2003. Ectonucleotidase in sympathetic nerve endings modulates ATP and norepinephrine exocytosis in myocardial ischemia. J. Pharmacol. Exp. Ther. 306:238-244.

40. Machida, T., Schaefer, U., Vorlova, S., Strickland, S., and Levi, R. 2004. Tissue-plasminogen activator releases norepinephrine from sympathetic nerves via a plasmin- and plasminogen-independent mechanism [abstract]. Circulation. 110(Suppl.):293-294.

41. Kitamura, Y., Go, S., and Hatanaka, K. 1978. Decrease of mast cells in $\mathrm{W} / \mathrm{W}^{v}$ mice and their increase by bone marrow transplantation. Blood. 52:447-452.

42. Hara, M., et al. 2002. Evidence for a role of mast cells in the evolution to congestive heart failure. J. Exp. Med. 195:375-381.

43. Dell'italia, L.J., et al. 1997. Compartmentalization of angiotensin II generation in the dog heart. Evidence for independent mechanisms in intravascular and interstitial spaces. J. Clin. Invest. 100:253-258.

44. de Lannoy, L.M., et al. 2001. Angiotensin converting enzyme is the main contributor to angiotensin I-II conversion in the interstitium of the isolated perfused rat heart. J. Hypertens. 19:959-965.

45. Levi, R., and Smith, N.C.E. 2000. Histamine $\mathrm{H}_{3}$-receptors: a new frontier in myocardial isch- emia. J. Pharmacol. Exp. Ther. 292:825-830.

46. Julius, S., 1993. Corcoran lecture. Sympathetic hyperactivity and coronary risk in hypertension. Hypertension. 21:886-893.

47. Dart, A.M., and Du, X.-J. 1993. Unexpected drug effects on autonomic function during myocardial ischaemia. Cardiovasc. Res. 27:906-914.

48. Kübler, W., and Strasser, R.H. 1994. Signal transduction in myocardial ischaemia. Eur. Heart J. 15:437-445.

49. Benedict, C.R., et al. 1996. Prognostic significance of plasma norepinephrine in patients with asymptomatic left ventricular dysfunction. Circulation. 94:690-697.

50. Selwyn, A.P., and Braunwald, E. 2001. Ischemic heart disease. In Harrison's principles of internal medicine. E. Braunwald et al., editors. McGraw-Hill. New York, New York, USA. 1399-1410.

51. Imamura, M., Lander, H.M., and Levi, R. 1996. Activation of histamine $\mathrm{H}_{3}$-receptors inhibits carrier-mediated norepinephrine release during protracted myocardial ischemia - comparison with adenosine $\mathrm{A}_{1}$-receptors and $\alpha_{2}$-adrenoceptors. Circ. Res. 78:475-481.

52. Walker, M.J., et al. 1988. The Lambeth Conventions: guidelines for the study of arrhythmias in ischaemia infarction, and reperfusion. Cardiovasc. Res. 22:447-455.

53. Seyedi, N., et al. 2005. Histamine $\mathrm{H}_{3}$-receptorinduced attenuation of norepinephrine exocytosis: A decreased protein kinase A activity mediates a reduction in intracellular calcium. J. Pharmacol. Exp. Ther. 312:1-9.

54. Markwell, M.A., Haas, S.M., Bieber, L.L., and Tolbert, N.E. 1978. A modification of the Lowry procedure to simplify protein determination in membrane and lipoprotein samples. Anal. Biochem. 87:206-210.

55. Hatta, E., Yasuda, K., and Levi, R. 1997. Activation of histamine $\mathrm{H}_{3}$-receptors inhibits carrier-mediated norepinephrine release in a human model of protracted myocardial ischemia. J. Pharmacol. Exp. Ther. 283:494-500. 